\title{
LAÇOS INDISSOCIÁVEIS: UM BREVE DEPOIMENTO
}

\section{- NELSON CORTES PACHECO JUNIOR ${ }^{1}$}

Mestre em Geografia pela Universidade Federal Fluminense (UFF). Pesquisador do NEPEC em Rede (UERJ), CRELIG (UFRRJ) e Geo.Con (UFF). E-mail: ncpj35@gmail.com

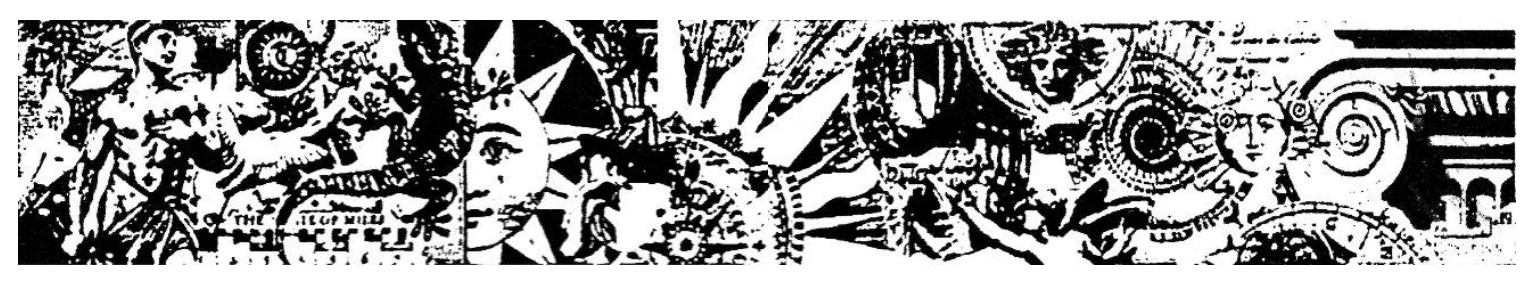

Como escrever um depoimento sobre uma revista que por sua excelência e luz própria fala por si mesma? Como contextualizar um periódico que podemos considerar como principal responsável pela disseminação da Geografia Cultural no Brasil?

Refletindo em relação a essa tarefa hercúlea, fiz a opção por realizar uma abordagem em relação ao grupo de pesquisa que é a alma da revista. Bem, na verdade, a Espaço e Cultura e o NEPEC se confundem, onde a existência de um é praticamente atrelada ao outro e vice-versa. O NEPEC, nasce em 1993 e podemos considerar que ele é um dos pilares sustentadores da revista que por sua vez, se apresenta ao mundo em 1995.

Ali, no NEPEC, os pensamentos foram se aflorando e as ideias sendo expostas, entre elas uma que para a Geografia, principalmente no período dos anos 1990 e 2000, era vista com um certo ar de desprezo por alguns ou anedota para outros ao ponto de perguntarem com certo ar de ironia: “isso é geografia”? Essa ideia ao qual me refiro era a Geografia da Religião, porém ledo engano de quem compartilhava tal maneira de pensar. Através dos estudos impulsionados pela Professora Zeny Rosendahl, acompanhada pelo Professor Roberto Lobato Corrêa e de alguns estudantes ávidos a buscarem compreender o "assunto que não era Geografia”, a “marginalizada” Geografia da Religião, 
crescesse orgulhosamente. Sem menosprezar as demais áreas do conhecimento geográfico e de maneira ímpar, os estudos nos conduziram ao entendimento de como a nossa relação com o Outro, buscando respeitar a alteridade deste, no sentido exposto por Levinas (2020), deve ocorrer quando abordamos as relações existentes do sagrado no lugar e como este influencia a nossa experiencia fática religiosa (HEIDEGGER, 2014).

Assim os mais variados temas foram se apresentando no âmbito do NEPEC. É quase impossível relacionar todos que direta ou indiretamente foram gerados a partir dos debates propostos pela professora Zeny Rosendahl e que de certa maneira contribuíram com as diferentes maneiras de pensar que depois seriam expostas nas diversas edições da Espaço e Cultura.

Entre as inúmeras pesquisas, destacamos algumas que exemplificam a riqueza em torno dos debates que envolvem Geografia, cultura e religião, como a difusão da Igreja Presbiteriana no Brasil (VASCONCELLOS, 1998) e a territorialidade da Igreja Católica Romana no Nordeste brasileiro (JESUS, 2005). Porém, não apenas a religião forma o vasto temário de ideias que constituem o NEPEC e a Espaço e Cultura, como ilustra Lamego (2006), quando da abordagem buscando interpretar a relação entre o círculo de Viena e a Geografia quantitativa.

E como os estudos em Geografia da Religião é uma das marcas do NEPEC, se fazia necessária compreender a mesma como fez Frangelli (2010), ou pensar em como a marca da Fé é uma característica marcante do Círio de Nazareth na cidade de Saquarema no Rio de Janeiro (TERRA, 2011).

Nem sempre a vivência religiosa ocorre nos grandes templos como nos foi apresentado através da etnografia do underground cristão brasileiro (CARDOSO, 2011), bem como nos lugares sagrados do sertão brasileiro (COSTA, 2011), ou mesmo nos espaços de peregrinação (SOUZA, 2017).

Entre as diversas abordagens, ocorreram aquelas em relação ao poder exercido pelas Ordens religiosas católicas que se irradiavam com tamanha força ao ponto de determinar territorialidades que deixam marcas que já perduram desde o período colonial brasileiro, como apresentado PACHECO JUNIOR (2013), TEIXEIRA (2012) e FRAGOSO (2015).

Ao mesmo tempo que se abordava a territorialidade religiosa advinda do passado que ainda se faz presente, também se deram os estudos relacionados a religião e ao "novo" tempo, onde acompanhando os rituais tradicionais nos espaços sagrados temos a tecnologia que conecta os fiéis ao seu culto, como salienta OLIVEIRA (2017) ao 
apresentar a hipermodernidade com as interfaces do sagrado na era 2.0. Que por sua vez também contribui para a existência do turismo religioso, como no caso da CidadeSantuário de Aparecida em São Paulo (BARBOSA, 2017).

Vale ressaltar que não apenas o catolicismo ou o protestantismo foram abordados no NEPEC, destaca-se que os estudos perpassaram diversas fronteiras alcançando a perspectiva do Islam Shiaa (ARROYO, 2019), o modo de ser cigano (GOMES, 2017), chegando ao lugar onde o ontem é história, o hoje é presente e o amanhã é mistério (NOVO, 2019). E pensar que todos os trabalhos citados são alguns dos vários que contribuíram cada um a sua maneira com a história do NEPEC e consequentemente com a Espaço e Cultura.

Quem imaginária que um milagre ocorrido em 1968 na longínqua Porto das Caixas, no município de Itaboraí - RJ, inspiraria um estudo sobre o espaço sagrado (ROSENDAHL, 1994)? E que na data de 09 de maio de 1994, ao ser defendido abriria o caminho para uma procissão na Geografia (2018), que não deve parar nunca e que continua a todo vapor seja pelos estudos temáticos sobre as relações entre Geografia, Religião e Cultura ou por este periódico que tão bem faz aos estudos geográficos.

É impossível pensar NEPEC e Espaço e Cultura separados, eles são indissociáveis. Não antes de terminar existe um integrante de toda essa história que não foi citado um "tal livro rosa" (ROSENDAHL, 2002), emblemático por si que para falarmos dele, seria necessário um outro depoimento. Nossa saudação em forma de ODE a este periódico e que sucessivos 25 anos venham sem cessar.

\section{REFERÊNCIAS BIBLIOGRÁFICAS}

ARROYO, Karina. Islam shiaa em perspectiva: novas considerações sobre a construção de materialidades móveis e o conceito de território, 2019. Tese (Doutorado em Geografia). Rio de Janeiro: Instituto de Geografia / Universidade do Estado do Rio de Janeiro.

BARBOSA, Ivo Francisco. Cidade- Santuário de Aparecida: devoção, turismo religioso e política. Espaço e Cultura, v. 1, p. 81-102, 2017.

CARDOSO, Diogo da Silva. Etnogeografia do Underground Cristão Brasileiro: concentração e dispersão das tribos em nome do Senhor, 2011 . Dissertação (Mestrado em Geografia). Rio de Janeiro: Instituto de Geografia / Universidade do Estado do Rio de Janeiro.

COSTA, Otávio José Lemos da. Canindé e Quixadá: construção e representação de dois lugares sagrados no sertão cearense, 2011. Tese (Doutorado em Geografia). Rio de Janeiro: Instituto de Geografia / Universidade Federal do Rio de Janeiro. 
FRAGOSO, Victor Murilo Maia. Grafia E̊ iconografia: traços identitários na Escola de Serviço do Senhor - Mosteiro de São Bento do Rio de Janeiro (1602-1802), 2015. Tese (Doutorado em Geografia). Rio de Janeiro: Instituto de Geografia / Universidade do Estado do Rio de Janeiro.

FRANGELLI, Patrícia. Estudando um Subcampo Intelectual Acadêmico: a geografia da religião no Brasil - 1989-2009, 2010. Dissertação (Mestrado em Geografia). Rio de Janeiro: Universidade do Estado do Rio de Janeiro.

GOMES, Carliane Sandes Alves. Ser e Estar Cigano: Identidade, Religião, Politica e Espaço, 2017. Dissertação (Mestrado em Geografia). Rio de Janeiro: Instituto de Geografia / Universidade do Estado do Rio de Janeiro.

HEIDEGGER, Martin. Fenomenologia da vida religiosa (trad. Enio Paulo Giachini / Jairo Ferrandin / Renato Kirchner). Petrópolis: Editora Vozes / Bragança Paulista: Editora Universitária São Francisco, 2014.

JESUS, Sandy Regina Cadete Barbosa de. A territorialidade da Igreja católica Romana no nordeste brasileiro, 2005. Dissertação (Mestrado em Geografia). Rio de Janeiro: Instituto de Geografia / Universidade do Estado do Rio de Janeiro.

LAMEGO, Mariana Araújo. Positivismo lógico e Geografia. Uma interpretação da relação entre o círculo de Viena e a Geografia quantitativa, 2006. Dissertação (Mestrado em Geografia). Rio de Janeiro: Instituto de Geografia / Universidade do Estado do Rio de Janeiro.

LEVINAS, Emmanuel. Totalidade e Infinito. Lisboa: Edições 70, 2020.

NOVO, Cássio Lopes da Cruz. Tomorrowland: ontem é história, hoje é presente, amanhã é mistério, 2019. Tese (Doutorado em Geografia). Rio de Janeiro: Instituto de Geografia / Universidade do Estado do Rio de Janeiro.

OLIVEIRA, Jefferson Rodrigues de. O on e o off da fé na hipermodernidade: a religião e as novas interfaces do sagrado na era 2.0. O exemplo no Vale do Paraíba (SP), 2017. Tese (Doutorado em Geografia). Rio de Janeiro: Instituto de Geografia / Universidade do Estado do Rio de Janeiro.

PACHECO JUNIOR, Nelson Cortes. Religião e Espaço: Disputas territoriais para a consolidação do espaço beneditino na cidade do Rio de Janeiro no século XVII. In: X Encontro Nacional da Associação Nacional de Pós-graduação e Pesquisa em Geografia. Campinas, 2013.

SOUZA, José Arilson Xavier de. Espaços de Peregrinação: ver o sentir o sagrado na Romaria de Nosso Senhor do Bonfim (TO), 2017. Tese (Doutorado em Geografia). Rio de Janeiro: Instituto de Geografia / Universidade do Estado do Rio de Janeiro.

TEIXEIRA, Claudia Barbosa. O papel das Ordens Leigas na configuração do espaço urbano da cidade do Rio de Janeiro: do Vice-Reinado ao final do Império, 2012. Tese (Doutorado em História). Rio de Janeiro: Instituto de Geografia / Universidade do Estado do Rio de Janeiro.

TERRA, Ana Carolina Lobo. A Marca da Fé no Círio de Nazareth: lócus da paisagem religiosa e do itinerário simbólico nos festejos de Saquarema, 2011. Dissertação (Mestrado em Geografia). Rio de Janeiro: Instituto de Geografia / Universidade do Estado do Rio de Janeiro.

VASCONCELLOS, Roseli Moraes. Difusão e Área de Abrangência da Igreja Presbiteriana do Brasil, 1998. Trabalho de Conclusão de Curso (Graduação em Geografia). Rio de Janeiro: Instituto de Geografia / Universidade do Estado do Rio de Janeiro. 
ROSENDAHL, Zeny. Porto das Caixas: espaço sagrado da Baixada Fluminense, 1994. Tese (Doutorado em Geografia). São Paulo: Faculdade de Filosofia e Ciências Humanas / Universidade de São Paulo, São Paulo.

ROSENDAHL, Zeny. Espaço e Religião: Uma abordagem geográfica. Rio de Janeiro: Ed. UERJ, 2002.

ROSENDAHL, Zeny. Uma Procissão em Geografia. Rio de Janeiro, Ed. UERJ, 2018. 